\title{
10th Growth Percentile
}

National Cancer Institute

\section{Source}

National Cancer Institute. 10th Growth Percentile. NCI Thesaurus. Code C98262.

An indication that an individual ranks the same or more than 10 percent of the reference population for a given attribute. 